\title{
PRODASEN: O SISTEMA DE INFORMAÇÕES DO SENADO FEDERAL COMO FONTE DE DADOS
}

\author{
Paula Matoski Butture ${ }^{1}$ \\ Ana Paula Lopes Ferreira ${ }^{2}$
}

\begin{abstract}
Resumo
O objetivo deste trabalho é mostrar a pertinência da utilização do Sistema de Informações do Senado Federal, o Prodasen, como fonte de dados para o estudo prosopográfico de elites políticas durante o período de 1918 a 1935. Este trabalho, de caráter fundamentalmente metodológico, apresenta os procedimentos utilizados para coleta e tabulação dos dados presentes na fonte e demonstra a utilidade e a conveniência de seu uso, contemplando especialmente os elementos que compõe o caminho utilizado no desenvolvimento da pesquisa. O trabalho parte da premissa de que a exposição de notas metodológicas é elemento constituinte da prática do cientista social e determinante dos resultados de sua pesquisa. Os principais achados apontam para a vantagem do Prodasen como fonte que torna o trabalho do pesquisador mais eficiente, além de apontar para a defasagem de fontes de dados complementares na medida do aumento do recuo histórico.
\end{abstract}

Palavras-chave: Prodasen; Prosopografia; Metodologia de pesquisa; Senado.

\section{Resumen}

El objetivo de este artículo es mostrar la relevancia del Sistema Informativo del Congreso del Senado Federal de Brasil - PRODASEN, como fuente de datos para un estudio prosopográfico de las élites, en el período de 1918-1935. Este trabajo, de propósito metodológico, presenta los procedimientos que se utilizan para recopilar y tabular los datos de PRODASEN demostrando la utilidad y conveniencia de su uso, sobre todo considerando los elementos que componen la ruta de la investigación. La premisa de este trabajo es que las notas metodológicas constituyen las prácticas del cientista social y son un factor determinante para los resultados de la investigación. Las principales conclusiones indican las ventajas de la utilización de PRODASEN como un origen de datos que aporta eficacia a la práctica del investigador, señalando al mismo tiempo el retraso de las fuentes de datos complementarios cuando se trata de la información más antigua.

Palabras clave: Prodasen. Prosopografía. Metodología. Senado.

\begin{abstract}
The aim of this article is to show the relevance of the Congressional Informational System of The Federal Senate of Brazil - Prodasen as a data source for a prosopographic study of elites, during the period of 1918 to 1935. This work has a methodological purpose and it presents the procedures used to collect and tabulate Prodasen's data, demonstrating the usefulness and convenience of its use, especially considering the elements that compose the research path. The premise of this work is that methodological notes constitutes the social scientist's practice and is a determining factor for the research results. The main findings indicates the advantages of Prodasen's use as a data source that brings efficiency to the researcher's practice, while pointing to the lag of supplementary data sources when dealing with older information.
\end{abstract}

Keywords: Prodasen. Prosopography. Research methodology. Senate.

\footnotetext{
${ }^{1}$ Psicóloga; mestranda em Ciência Política pela Universidade Federal do Paraná.

${ }^{2}$ Internacionalista, mestranda em Ciência Política pela Universidade Federal do Paraná.
} 


\section{INTRODUÇÃO}

A proposta deste texto é demonstrar a pertinência do Sistema de Informações do Senado Federal como fonte de dados para uma pesquisa prosopográfica sobre as elites políticas brasileiras, em especial durante a Primeira República, ou, mais precisamente, numa pesquisa sobre os senadores eleitos entre 1918 e 1935 - 31 a $37^{\circ}$ legislatura. A coleta de dados fez parte de uma pesquisa construída pelo Núcleo de Pesquisa em Sociologia Brasileira da Universidade Federal do Paraná (NUSP), a qual tinha o objetivo de estudar os processos complexos de profissionalização política de senadores e deputados federais no Brasil entre 1889 e 2014. O recorte temporal de 1918 a 1935 foi parte desta pesquisa de maior abrangência, e apresenta como diferencial o fato de representar a mudança da República Velha para o Estado Novo, incluindo a Revolução Tenentista de 1930, a qual colocou Getúlio Vargas no poder.

O estudo prosopográfico, compreendido conforme a definição de Lawrence Stone, como "a investigação das características comuns de um grupo de atores na história por meio de um estudo coletivo de suas vidas" (STONE, 2011), consiste numa investigação de dados biográficos de uma população específica, escolhida através de critérios predefinidos, os quais, uma vez justapostos e examinados, podem ser testados com o objetivo de encontrar correlações internas ou em relação a comportamentos e ações. A investigação prosopográfica, ou estudo de biografias coletivas, tem sido um dos principais métodos para os pesquisadores de elites políticas, possibilitando um refinamento metodológico no estudo dos atores situados no topo da hierarquia social, permitindo compreender a complexidade de suas relações e de seus laços objetivos com o conjunto ou com setores da sociedade (HEINZ, 2011). Suas vantagens estão na precisão dos dados e na possibilidade de proporcionar diversos tipos de investigação (COSTA \& GOUVÊA, 2007).

Considerando a lacuna apontada por Costa e Gouvêa (2007) no estudo acadêmico brasileiro sobre elites políticas, demonstrada pela defasagem de materiais documentados e abundantes sobre elites políticas, procuramos, neste trabalho, cotejar a utilização da fonte histórica chamada Prodasen na constituição de biografias coletivas ou prosopografias das elites brasileiras para o período de 1918 a 1935. As biografias têm em comum o fato de serem biografias "institucionais", isto é, o produto objetivo do encontro entre um indivíduo detentor de uma identidade social e uma instituição por si mesma produtora de categorias identitárias. 
Partimos da compreensão que a exposição de notas metodológicas de pesquisa não são mero apêndice do trabalho intelectual, mas se configura como um montante de elementos constituintes da prática do cientista social e determinante dos resultados de sua pesquisa, cabendo, assim, expô-la de maneira a legitimar o trabalho e colocá-lo em condição de ser avaliado (SCHRITZMEYER, 2004).

O trabalho está organizado da seguinte forma: inicia com uma exposição específica sobre o Prodasen; em seguida, apresenta as dificuldades encontradas na utilização do instrumento e as soluções empenhadas para resolvê-las; na terceira parte traz uma discussão sobre as vantagens e desvantagens do instrumento em comparação ao Dicionário Histórico Biográfico da Fundação Getúlio Vargas; e, por fim, mostra um passo a passo do processo de coleta de dados.

\section{PRODASEN COMO FONTE DE DADOS}

A fonte de dados utilizada na pesquisa partiu da Secretaria de Tecnologia da Informação do Senado Federal, órgão responsável por manutenção, atualização e processamento de bancos de dados do Senado - PRODASEN, que tem por competência prover e gerir o Senado Federal e, complementarmente, todo o Poder Legislativo, de serviços, soluções e suporte de tecnologia de informação3.

A Coordenação de Arquivo desta Secretaria alimenta o banco de dados "Biografia dos Senadores Brasileiros (BSEN) - 1826-2013”, com informações obtidas através de material bibliográfico histórico e de informações cedidas pelas famílias dos parlamentares. Este banco hoje conta com 1.438 biografados. Embora recentemente se valha de informações cedidas por assessorias parlamentares, no recuo histórico estas informações advêm, prioritariamente, de dados bibliográficos. O Prodasen, termo que será utilizado para designar a fonte, proveu para a presente pesquisa dados significativos sobre os

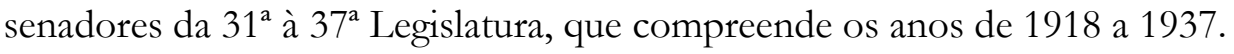

A fonte serviu como base para alimentar uma planilha que destacava as seguintes informações: dados de identificação, filiação e filiação partidária, carreira burocrática,

\footnotetext{
${ }^{3}$ Dentre outras competências, o PRODASEN tem o objetivo de implementar a estratégia de tecnologia da informação; propor inovações nos processos finalísticos e de apoio do Senado, com uso de tecnologia da informação; propor padrões, normas, métodos e processos para uso da tecnologia da informação e monitorar sua aplicação; integrar iniciativas de adoção de novas soluções de tecnologia da informação por outras unidades da Casa; gerir a segurança da informação do Senado no âmbito da tecnologia da informação; gerenciar os riscos operacionais do Senado com origem em tecnologia da informação; e executar outras atividades correlatas (dados fornecidos pelo Senado Federal).
} 
carreira políticas, vínculos familiares, informações ocupacionais e associativismo. Ao todo foram 401 senadores listados entre a $31^{\mathrm{a}}$ e a $37^{\mathrm{a}}$ legislaturas.

O material fornecido pelo Prodasen está dividido em sete arquivos (um arquivo para cada legislatura), cada qual com cerca de 60 senadores, em média. Os arquivos estão organizados por ordem alfabética e contêm os seguintes blocos de informações: 1. Dados de identificação: nessa área são apresentados o nome completo e o nome parlamentar, data de nascimento e óbito, naturalidade, estado civil, cônjuge, sexo e filiação; 2. Dados sobre filiação partidária: sigla do partido, ano de entrada e saída do partido; 3. Dados sobre profissões: profissões exercidas ao longo da vida; 4. Dados sobre cargos exercidos: cargos públicos e eletivos (separados por cargo com os respectivos anos e local de exercício); 5. Dados familiares: informações sobre a profissão dos ascendentes, e, porventura, do exercício de cargos públicos e/ou eletivos; 6. Trabalhos publicados: livros, discursos, participação na elaboração de constituições; 7. Outras informações: item no qual é possível levantar informações sobre associativismo, direção partidária, exercício profissional e demais dados relevantes sobre a vida do político em questão. Essa divisão nas fichas permite localizar mais facilmente as informações, diminuindo o tempo de coleta dos dados.

O Prodasen não é um dicionário biográfico histórico. Ele leva em conta apenas as informações de identificação do Senador conforme coletadas pelos historiadores do Senado e existem biografias mais valorizadas que outras. Assim, fatos como origem do capital do Senador não ficam evidenciadas nas informações, sendo as informações como estudos universitários ou trajetória profissional maiores indicadores dos recursos e estratégias profissionais adotadas pelo parlamentar.

No início do tratamento dos dados fornecidos pelo Prodasen, foi possível identificar que certos aspectos - como a datação histórica dos fatos, por exemplo - estava subnotificada. Havia poucas informações sobre os anos de entrada e saída de cargo e partidos e nenhuma informação sobre o ano de formação do parlamentar. Em um número reduzido, estavam ausentes informações sobre ano de nascimento e/ou óbito do parlamentar. Em contrapartida, as indicações sobre os cargos eletivos ocupados estavam bastante completas e nomeadas de forma exata conforme a época - como a ocupação de cargo de "senador estadual" e "presidente de estado", o que, por um lado, toma mais tempo do pesquisador, por outro, permite o conhecimento dos pormenores dos cargos parlamentares de cada época. Destaca-se aqui a predominância de estudos universitários e 
trajetória profissional, em detrimento de dados a respeito da origem social dos constituintes, que digam respeito a família, idade ou religião.

O desafio que se colocou foi compreender, dos cargos ali elencados, quais os anos de exercício correspondentes às legislaturas, isto é, no caso de um político que ocupou o cargo de senador por cerca de 30 anos, foi necessário fazer o cálculo para dividir este exercício entre as legislaturas existentes, pois, conforme assinalado, não há a datação exata de entrada e saída nos cargos. Aos poucos, foi se tornando evidente que a separação por legislatura não estava adequada e que havia senadores de legislaturas que não correspondiam àquela em que estavam contidos, de modo que as biografias tiveram de ser tomadas num panorama geral, e não mais em separado. Deste ponto, vale destacar que no arquivo da $36^{a}$ legislatura havia 21 senadores, sendo que nenhum deles, de fato, exerceu o cargo neste período, uma vez que o Congresso foi dissolvido em 1930, em decorrência da Revolução de 3 de outubro daquele ano - golpe de estado que depôs o presidente Washington Luís e impediu a posse do presidente eleito Júlio Prestes -, e só foi reaberto em 1934. Grande parte dos senadores ali citados estava presente em outras legislaturas.

De modo específico, no momento de separação dos dados em blocos de informação, nota-se a falta de algumas informações pontuais, as quais serão descritas a seguir.

\section{AUSÊNCIAS DE DADOS NO PRODASEN}

Conforme exposto, as informações constantes sobre cada parlamentar separam-se em blocos de informações, quais sejam: bloco 1 - dados de identificação; bloco 2 - dados de filiação partidária; bloco 3 - dados de profissões exercidas; bloco 4 - dados sobre cargos públicos e eletivos; bloco 5- dados familiares; bloco 6- dados sobre trabalhos publicados; e bloco 7 - outras informações. As informações, embora padronizadas, são pouco uniformes, conforme se verifica nos Quadros 1 e 2. Os dados apresentados a seguir referem-se às ausências constantes em cada um destes blocos.

O primeiro bloco, com dados de identificação, contém as principais informações a respeito dos senadores, como nome completo, nome parlamentar, naturalidade e data de nascimento e óbito. No universo de 401 parlamentares, todas continham o nome completo, entretanto em 4,23\% dos casos (17 biografias) estavam ausentes o nome parlamentar. Para estes casos, foi adotado o nome completo. No que se refere às datas de nascimento e óbito dos senadores, houve inexatidão nas informações: em 4,73\% dos casos 
(19 casos) não consta a data de nascimento e, em número mais expressivo, 22,44\% dos casos (90 casos) não consta data de óbito. Ainda no bloco identificação, constam 7 casos, num percentual de 1,74\% do total, sem informação sobre estado de nascimento e 2,44\% (9 casos), sem informação sobre município de nascença do senador.

Ainda em relação ao local de nascimento, é relevante notar que o Prodasen preserva os nomes originais dos municípios da época, ainda que estes tenham se alterado no decorrer dos anos. Nota-se, ainda, que no que diz respeito ao nome do local de nascença, há casos como o do Senador Dyonisio Ausier Bentes, que exerceu o cargo durante a $35^{\mathrm{a}}$ legislatura, no qual não consta cidade, tampouco estado de nascimento, havendo apenas a informação sobre a fazenda em que nasceu.

Foram citadas cidades como São Francisco de Paula e Amarante, que aparecem em dois estados diferentes: no caso de São Francisco de Paula, existe ocorrência no Rio Grande do Sul e em Minas Gerais, e no caso da cidade de Amarante, há homônimos no Maranhão e no Piauí. Para a descoberta do estado correto, foi preciso realizar uma pesquisa nos sítios de internet oficiais das prefeituras em questão, de modo a descobrir a data de fundação dos municípios e relacioná-las com o período de nascença do senador em tela. No caso de São Francisco de Paula, por exemplo, constatou-se que a fundação em Minas Gerais ocorreu apenas no ano de 1963, enquanto a fundação no estado do Rio Grande do Sul é datada de 1878, trazendo esclarecimentos para a pesquisa. No caso de Amarante a situação foi semelhante: a cidade de Amarante, no Maranhão, foi fundada tão somente em 1963, induzindo a compreensão de que o senador nasceu no estado do Piauí.

No segundo bloco, que contém dados sobre filiação partidária, com ano de entrada e saída dos partidos, constatou-se uma defasagem considerável. A datação, mais uma vez, foi o ponto mais ausente. Em 50,37\% dos casos (202 do total), estavam ausentes as informações sobre o ano de entrada no partido e em 57,85\% dos casos (232) não havia informação sobre o ano de desvinculação ao partido. Em 31,67\% do universo (127 casos) não consta nenhuma informação partidária, ao que cabe conjecturar se havia relação com a não filiação partidária do senador ou se pela falta de informação fornecida pelo PRODASEN. Não houve nenhuma relação entre a legislatura e a ausência de filiação partidária, em todas as legislaturas estas ausências ficaram em torno de 35\% de cada legislatura. Nota-se, no entanto, que na $37^{a}$ legislatura $100 \%$ dos casos contém informações sobre filiação partidária. 
Em número reduzido, isto é, apenas 2 casos, consta existência de filiação partidária sem especificar o partido. Além disto, o Prodasen não traz os nomes dos partidos por extenso, trazendo equívocos na comparação entre partidos de siglas idênticas e nomes diferentes, como no caso do PRM, que pode significar tanto Partido Republicano Mineiro, quanto Partido Republicano Maranhense, principalmente ao se considerar a presença massiva de partidos estaduais durante a época contemplada na pesquisa.

No terceiro bloco, de profissões exercidas, constam as informações sobre a profissão de exercício e de formação. Não consta aqui o ano de graduação, de modo que o cálculo para esta informação foi feito com base na idade de 24 anos, considerando o tempo, em média, para uma graduação de nível superior.

Ocorre, em alguns casos, de o senador ter formação militar e graduar-se como engenheiro dentro da própria instituição militar, informação que fica pouco evidente na leitura do instrumento. Ainda, no caso dos senadores que provêm de carreira militar, não fica claro em qual das forças armadas ele prestou serviço, tampouco o ano de entrada e saída das mesmas.

Em seguida, no bloco quatro, constam dados sobre a carreira profissional dos senadores, com informações sobre cargos burocráticos e cargos eletivos. Inclui-se aqui a localidade e as datas de entrada e saída no exercício profissional. Neste item, a ausência de datas é a principal defasagem. Referente aos cargos burocráticos tem-se que, em 55,86\% dos casos (224 do total), consta informação de que o senador exerceu alguma atividade burocrática. Deste universo, 40,65\% (91 casos) estão ausentes das datas de entrada e $57,14 \%$ dos casos (128 do total) estão sem data de saída de algum dos cargos. A ocorrência de ocupação de cargos burocráticos é uniforme entre as legislaturas, havendo um aumento pronunciado de ocorrências na $37^{\mathrm{a}}$ legislatura.

As informações sobre cargos eletivos são a parte mais completa do Prodasen. Em alguns casos consta, inclusive, o número de votos obtidos pelo político em determinado cargo. É, notadamente, o bloco que contém maior número de informações, e as dificuldades, novamente, dizem respeito às datas. O Prodasen também preserva aqui a nomeação dada aos cargos à época, como os cargos de "lente" (professor) e diretor de higiene. Cabe destacar que neste bloco nem sempre estão discriminadas as legislaturas referentes aos cargos, de modo que, a partir da soma dos anos de exercício no cargo, é necessário fazer o cálculo para caber nas respectivas legislaturas.

Três categorias ressaltam nas biografias: há sobrerrepresentação de profissões intelectuais, como juristas, alto funcionalismo público e jornalistas, e das profissões de 
Estado, que faz eco à sub-representação de empresários privados e ausência de negócios comerciais. A questão do engajamento político também é um traço característico dos parlamentares. O quadro é claro: cultura, estado, engajamento constituem as principais fontes dos parlamentares que ocupam assento no Senado Federal durante a Primeira República.

O quinto bloco é composto por dados familiares. É um dos blocos mais completo das biografias, onde pode se observar a ligação entre os membros familiares da elite política, inclusive em relações de matrimônio. Não raro observam-se sogros ou cunhados com cargos políticos eminentes, influência e pertencentes a famílias com tradição na política, indo ao encontro da tese de linhas oligárquicas como fonte de capital político na Primeira República.

O bloco seis refere-se aos trabalhos publicados pelo senador. Tendo em vista a grande ocorrência de cargos de jornalista, é comum que este bloco esteja preenchido com diversas obras dos parlamentares, como livros, poemas, discursos e até mesmo participação na elaboração da Constituição do Brasil.

O sétimo bloco, denominado outras informações, traz, ainda, dados sobre produção literária, assim como dados sobre associativismo, participação em comissões do senado, missões diplomáticas, cargos de importância na carreira burocrática ou militar, entre outros; de difícil mensuração e sem padronização uniforme, traz informações singulares a cada caso, havendo, inclusive, senadores dos quais este bloco de informações está vazio.

\section{O DICIONÁRIO HISTÓRICO BIOGRÁFICO BRASILEIRO (DHBB) COMO FONTE COMPLEMENTAR}

$\mathrm{Na}$ busca de completar informações sobre os parlamentares, a fonte PRODASEN teve de ser confrontada com outras, também de caráter histórico biográfico, em especial o Dicionário Histórico Biográfico Brasileiro da Fundação Getúlio Vargas (DHBB).

O DHBB é uma obra de referência voltada para a história do Brasil no período pós 1930, construído pelo Centro de Pesquisa e Documentação da História Contemporânea do Brasil (CPDOC), a Escola de Ciências Sociais da Fundação Getúlio Vargas. O DHBB tem a vantagem de trazer informações detalhadas e bem exploradas, principalmente no que diz respeito às datas e informações sobre associativismo, mas, por não adotar um padrão na disposição de informações, e ter como característica a 
apresentação de informações de forma linear, em narrativa corrida, torna a coleta dos dados pretendidos mais árdua e morosa. É neste contraste que se observa um dos pontos mais positivos do Prodasen: as informações são claras e objetivas, tornando a coleta do pesquisador mais ágil e respondendo bem à ordem das informações visadas na coleta.

Ao comparar a base de dados das fichas biográficas do Prodasen e dos verbetes biográficos do DHBB, tornam-se clara as vantagens e desvantagens do uso de um ou de outro. Enquanto as biografias do PRODASEN trazem os dados apresentados de uma maneira mais organizada e objetiva do que o DHBB, essa diferença resulta diretamente no tempo que a coleta de dados leva para ser realizada.

O DHBB foi utilizado em 70 casos (17\% do total). Seu uso foi limitado por apresentar informações sobre o período pós 1930, de modo que os dados sobre as legislaturas anteriores a este período vão se tornando escassas a partir da $35^{\mathrm{a}}$ legislatura. No Quadro 1, pode-se observar a quantidade de consultas realizadas ao DHBB em cada legislatura, evidenciando que esta consulta aumenta consideravelmente na $37^{a}$ legislatura. 


\section{Quadro 1 - Consultas ao DHBB por Legislatura}

\begin{tabular}{|r|r|r|}
\hline \multirow{2}{*}{ LEGISLATURAS } & \multicolumn{2}{|l|}{ CONSULTAS AO DHBB } \\
\cline { 2 - 3 } & \multicolumn{1}{|l|}{$\mathrm{N}^{\mathrm{O}}$} & $\%$ \\
\hline 31 & 4 & $6 \%$ \\
\hline 32 & 5 & $7 \%$ \\
\hline 33 & 9 & $12 \%$ \\
\hline 34 & 4 & $5 \%$ \\
\hline 35 & 11 & $15 \%$ \\
\hline TOTAL & 37 & $82 \%$ \\
\hline
\end{tabular}

É relevante ressaltar que há uma relação entre ausência de filiação partidária ( $0 \%$ na $37^{\mathrm{a}}$ legislatura, conforme apontado anteriormente), e a consulta ao DHBB, predominante nesta legislatura. Ao mesmo tempo, aumentam os dados sobre cargos burocráticos $(78 \%$ dos casos da $37^{a}$ legislatura constam cargos burocráticos) e dados de identificação (estão ausentes somente em dois casos desta legislatura). É importante destacar que em 100\% dos casos em que houve consulta ao DHBB consta o ano de graduação do parlamentar.

Abaixo um quadro comparativo entre os principais dados coletados na planilha. Fica evidente que na $37^{a}$ legislatura há maior ocorrência de informações.

\section{Quadro 2 - Principais lacunas na coleta de dados}

\begin{tabular}{|r|r|r|r|r|r|l|}
\hline LEGISLATURA & $\begin{array}{l}\text { Data de } \\
\text { nascimento }\end{array}$ & $\begin{array}{l}\text { Data de } \\
\text { óbito }\end{array}$ & Naturalidade & $\begin{array}{l}\text { Ano de } \\
\text { filiação } \\
\text { partidária }\end{array}$ & $\begin{array}{l}\text { Entrada } \\
\text { cargo }\end{array}$ & $\begin{array}{l}\text { Saída } \\
\text { cargo }\end{array}$ \\
\hline 31 & $7 \%$ & $19 \%$ & $4 \%$ & $51 \%$ & $60 \%$ & $94 \%$ \\
\hline 32 & $3 \%$ & $23 \%$ & $4 \%$ & $55 \%$ & $68 \%$ & $97 \%$ \\
\hline 33 & $5 \%$ & $27 \%$ & $3 \%$ & $51 \%$ & $72 \%$ & $95 \%$ \\
\hline 34 & $3 \%$ & $27 \%$ & $0 \%$ & $52 \%$ & $70 \%$ & $96 \%$ \\
\hline 35 & $8 \%$ & $25 \%$ & $1 \%$ & $53 \%$ & $69 \%$ & $94 \%$ \\
\hline 37 & $0 \%$ & $5 \%$ & $0 \%$ & $33 \%$ & $51 \%$ & $18 \%$ \\
\hline TOTAL & $5 \%$ & $22 \%$ & $2 \%$ & $50 \%$ & $66 \%$ & $87 \%$ \\
\hline
\end{tabular}




\section{CONSIDERAÇÕES FINAIS}

A investigação sobre as biografias permite observar que lugar é dado aos elementos constitutivos da identidade. Este fato também diz a respeito ao que era considerado importante para categorizar a elite durante a Primeira República. É possível observar que certas informações tidas como privadas - família, raça, religião, físico - estão ausentes nas biografias, a não ser que haja parentesco com pessoas dentro da política. Já as informações públicas são muito presentes. O capital econômico é ignorado, enquanto o capital cultural figura regularmente nas biografias, assim como as menções de engajamento público. São destacados os elementos da história pessoal que colocam em evidência a ligação do parlamentar aos princípios éticos da causa ou a defesa de um bem comum.

Flávio Heinz (1999) encontra nos estudos de anuários do tipo Who’s Who vantagens em estudos de elites, por reunirem informações sistemáticas de caracterização pessoal dos biografados, como ascendência e descendência familiar, participação em clubes, escolaridade, atuação política e empresarial. Dados desta qualidade foram encontrados no Prodasen de forma sistematizada e, na maior parte dos casos, como fonte única e exclusiva, e, principalmente, como uma das poucas bases de dados brasileiras cujo recuo histórico remonta o final do século XIX e início do XX. Para o levantamento de dados sobre elites políticas brasileiras, quanto maior o recuo histórico, maior a falta de informações e a necessidade de procura de fontes alternativas.

A defasagem do estudo histórico exige do pesquisador um trabalho essencialmente investigativo e exploratório, além de decisões metodológicas para avaliar qual dado realmente interessa. A questão da ocupação, por exemplo, constitui um problema específico que exige decisões metodológicas no momento da coleta de dados. Conforme Costa, Codato, \& Massimo (2013), é necessário fazer uma série de decisões metodológicas para estabelecer a profissão de origem de um parlamentar que influenciam a classificação e, então, as análises. Com um campo de três possíveis ocupações, decidimos por inserir aquelas exercidas por mais tempo pelo indivíduo e que, certamente, influenciaram seu percurso até o cargo de Senador ser ocupado.

Este processo facilita a adesão de outros pesquisadores que necessitem engendrar a mesma tabulação. Na medida em que novas informações foram agregadas e que os dados foram tratados, os campos foram se tornando mais detalhados e passíveis das mais variadas utilizações e comparações, permitindo discriminar padrões de carreira, ascensão social e 
vínculos com redes sociais e familiares, permitindo a reconstrução de uma parte de um período importante da histórica política brasileira.

\section{REFERÊNCIAS BIBLIOGRÁFICAS}

Centro de Pesquisa e Documentação de História Contemporânea do Brasil/Fundação Getúlio Vargas. Dicionário bistórico biográfico brasileiro. Disponível em: http://www.fgv.br/cpdoc/busca/Busca/BuscaConsultar.aspx acesso: jul. 2013.

COSTA, L. D., CODATO, A., \& MASSIMO, L. 2013. Codificando profissões em estudos de elites políticas: uma discussão metodológica e tipológica. IN: Colóquio elites em diferentes escalas: teoria e metodologia no estudo de grupos dirigentes.

COSTA, L. D., \& GOUVÊA, J. C. 2007. Elites e historiografia: questões teóricas e metodológicas. Revista de Sociologia E Política, (2002), 251-255.

HEINZ, F. M. 1999. Do uso do Who's Who e de outros dicionários biográficos na construção de biografias coletivas das elites sociais e politicas do Brasil contemporâneo. Barbarói, Santa Cruz do Sul, n. 10, p. 49-60, jan./jun.

HEINZ, F. M. 2011. História social de elites. São Leopoldo: Oikos.

SCHRITZMEYER, A. L. P 2004. Sortilégio de saberes: curandeiros e juizes nos tribunais brasileiros (1900-1990). São Paulo: IBCCRIM.

Senado Federal. Biografia dos Senadores Brasileiros (BSEN) - 1826-2013.

STONE, L. 2011. Prosopografia. Revista de Sociologia e Politica, 19(39), 115-137. 